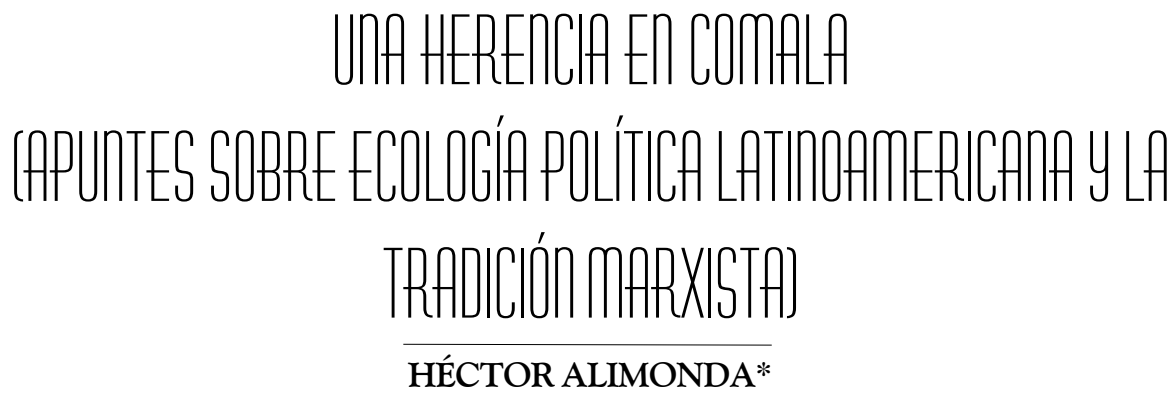

Otra vez: a la memoria de Pancho Aricó, sábado al mediodía, un vermouth en "El Parnaso", frente a la plaza de Coyoacán

"Vine a Comala porque me dijeron que acá vivía mi padre, un tal Pedro Páramo. Mi madre me lo dijo. Y yo le prometí que vendría a verlo en cuanto ella muriera." Juan Rulfo, Pedro Páramo

"Alguien, un crítico ruso, el crítico ruso Iuri Tinianov afirma que la literatura evoluciona de tío a sobrino (y no de padres a hijos). Expresión enigmática que nos ha de servir por el momento ... "Ricardo Piglia, Respiración Artificial

"Justo ahora, que sabía todas las respuestas, me cambiaron las preguntas" Pintada en una pared de Montevideo

P

Para moderar la ambición que parece pretender este texto, prefiero darle explícitamente el carácter de "apuntes"; solamente unos esbozos muy generales, que ojalá sean capaces de indicar un camino posible para viajeros interesados en transitar un territorio lleno de escollos, algunos edificios derrumbados, algunos profetas aún predicando en el desierto. Y, sobre todo, laberintos, espejos deformantes y espectros. Se trata solamente de esbozar un "mapa cognitivo" (JAMESON, 1996: 76-79) que pueda servir como materia prima para localizar una discusión esclarecedora.

En primer lugar, quiero indicar algunas características relevantes que, me parece, constituirían puntos de partida verosímiles para una Ecología Política latinoamericana. Siguiendo a Derrida (1994), creemos que la vigencia de estas características no se ejerce puntualmente, en la forma de "determinaciones", sino como una presencia espectral de lo ausente, constitutiva de los lazos sociales básicos y de los imaginarios que, aún inmaterial, no resulta menos concreta. Hasta el lector más distraído verá que también nos interrogamos sobre la propia identidad latinoamericana. Además, 
será evidente que - desde éste punto de vista - la perspectiva de una Ecología Política supone la construcción de una historia ambiental de la región.

A continuación, queremos indicar alguna aproximación posible, y que creemos legítima, de esa Ecología Política con la herencia de Marx. El tema ya ha sido transitado de forma competente por otros autores (MARTÍNEZ ALIER, 1995; BENSAID, 1999), y sólo pretendemos insistir en una de sus dimensiones, justamente la que se refiere a las fantasmagorías. Y, por último, queremos indicar, a través de Alexander Herzen y de Nikolai Danielson, que la primera gran tradición heredera de Marx, la del socialismo ruso del siglo XIX, con la riqueza de sus preguntas sobre la identidad nacional y la condición periférica, es una fuente donde el pensamiento latinoamericano, y en especial la Ecología Política, pueden encontrar aún espejos empañados capaces de sugerir reflexiones contemporáneas.

La relación entre las tres partes que componen el trabajo no es directa, y posiblemente no formen un todo coherente. Bueno, justamente de eso se trata ...

\section{LA ECOLOGÍA POLÍTICA LATINOAMERICANA}

Quizás podemos comenzar con una reflexión de Gustavo Lins Ribeiro (2001) sobre la antropología latinoamericana, como forma de presentar la radical ambigüedad que atraviesa al pensamiento social de la región, que no es sino un síntoma de un peculiar conflicto de identidad. "Por un lado, no somos miembros de los ricos centros imperiales (de hoy o del pasado) como lo son nuestros colegas norteamericanos o europeos, pero compartimos con ellos la herencia formativa de los cánones de Occidente. Por otro lado, no somos educados en grandes tradiciones no-occidentales como lo son nuestros colegas asiáticos, pero compartimos con ellos historias de inserción en posiciones subordinadas internas a imperios capitalistas occidentales" (RIBEIRO, 2001: 162).

Por detrás de esta ambigüedad y de esta crisis de identidad, la investigación genealógica encuentra la "escena primaria", la "zona de indecibilidad" donde se originan los espectros, que "abre una ventana desde dónde es posible percibir la constitutiva contingencia del capitalismo" (de IPOLA, 1997: 160). Se trata de la acumulación originaria, con su carga de violencia, despojo, sangre y barro, que va siendo recubierta fantasmagóricamente en el capitalismo estabilizado, pero que es recreada en sus fronteras de expansión. Se trata también de los dispositivos espectrales del fetichismo de la mercadería, del carácter fantasmático de la renta de la tierra, de la realimentación del imaginario político por las apariciones (trágicas o farsescas) del pasado. También la memoria de las luchas de resistencia aparece como fantasmas del pasado, que los oprimidos convocan para mirarse en ellos y extraer inspiración o coraje para las luchas del presente.

Una reflexión latinoamericana sobre la Ecología Política de nuestra región tiene como referencia fundante el tremendo trauma de la conquista del continente por los europeos. Al decir esto, no estamos encadenando la reflexión contemporánea en una determinación monista omniexplicativa, como en algunos excesos de la "teoría de la dependencia". Primero, porque nos estamos refiriendo a una de las experiencias más violentas y radicales de la historia de la humanidad (pensemos solamente en las 
transformaciones en el valle de México entre 1520 y 1540!). Pero también porque no la tomamos literalmente como factor causal de toda la historia posterior, sino como ruptura que da origen a la particular heterogeneidad y ambigüedad de las sociedades latinoamericanas, y como una presencia / ausencia espectral en la constitución de los lazos e imaginarios sociales.

a) La conquista europea significó una dramática interrupción en el curso histórico natural de la población americana, que en la época representaba 20\% de la humanidad. Grandes culturas desaparecieron sin dejar muchos más rastros que las ruinas de sus ciudades; pero también desaparecieron pueblos y naciones indígenas no urbanas, sin dejar ningún vestigio. Se trató de un gigantesco etnocidio, que implicó el sacrificio gratuito de universos simbólicos y de tecnologías adaptadas a diferentes ecosistemas del continente, basadas en siglos de paciente observación de los procesos naturales.

b) Al mismo tiempo, es necesario recordar que este etnocidio tuvo expresión muy concreta en la espeluznante mortalidad que arrasó a las poblaciones indígenas. No se trató solamente de la violencia directa de los conquistadores, de los trabajos forzados, del hambre provocada por la desorganización de los sistemas agrícolas. Fue consecuencia también del efecto devastador que tuvieron, sobre la población de América, hasta entonces aislada del resto de la humanidad (y, por lo tanto, con escasa inmunidad), los microorganismos patógenos transplantados al continente por los europeos (CROSBY, 1993; TUDELA, 1992).

c) Pero junto con esta catástrofe demográfica, se produjo también una gigantesca migración de flora y fauna extra-americana, que rápidamente se extendió por la superficie del continente, y que en algunos lugares produjo - en pocos años radicales transformaciones de los ecosistemas y del paisaje (HÉRNANDEZ BERMEJO/ LEÓN, 1992; FERRÃO, 1992). En la mayoría de los casos, éstos fenómenos contribuyeron al colapso de los sistemas agrícolas y de recolección nativos. En unas pocas situaciones, como las de las llanuras del Río de la Plata y del Norte de México, los habitantes fueron capaces de sacar provecho de éstas transformaciones que, paradójicamente, potenciaron su capacidad de resistencia frente a los invasores (CROSBY, 1993).

d) Simultáneamente, hacían la travesía del Atlántico - en sentido contrario - vegetales de gran valor alimenticio hasta entonces desconocidos en Europa, junto con saberes agrícolas a ellos vinculados que habían sido desarrollados durante siglos por los nativos de América, y que tuvieron en el continente de adopción consecuencias demográficas y sociales de primera magnitud.

e) Gran parte de éstos procesos se desarrollaron espontáneamente, con independencia de la voluntad y de las intenciones del poder imperial. Sin embargo, formaron parte de un gigantesco dispositivo de reordenamiento social y ambiental de los territorios en función del establecimiento de lo que ha sido denominado "economía de rapiña" (CASTRO, 1996). 
f) Este reordenamiento significó también una reterritorialización del espacio continental, en una escala hasta entonces desconocida por la humanidad. Cada punto del continente fue redimensionado según una red multifacética de poder que respondía a la lógica y a las capacidades concretas de acción y de presencia efectiva de la potencia imperial. Lo local latinoamericano se constituyó según una relación con un global hegemónico. Las ciudades surgieron como producto de ese reordenamiento territorial, como centros de guarnición y de administración, como gestos del poder, y no como progresivo adensamiento de relaciones sociales según las virtualidades del territorio. Fue antes la ciudad capital que la aldea (MARIÁTEGUI, 1995; RAMA, 1985).

g) Esto llevó a la formación de sociedades netamente concentradoras de poder político, social y económico, caracterizadas por profundos cortes étnico-culturales y por la rigidez de las estructuras sociales que incluyeron la esclavitud africana. La lógica de la "economía de rapiña", cuyas ganancias dependían de la vinculación con el mercado global, alimentó y fue retroalimentada por estos mecanismos de exclusión. En todas partes, con dimensiones e intensidad variables, se incrementó la tendencia a la constitución de la naturaleza en mercadería (POLANYI, 1957, cap. 15). ${ }^{1}$

h) Sin embargo, esta reorganización social altamente excluyente no significó la desaparición absoluta de los pueblos indígenas o de sus culturas. Recomposiciones demográficas y mestizajes fueron constituyendo un magma cultural de origen americano, europeo y africano, donde sobrevivieron antiguos saberes sobre la naturaleza y se crearon otros nuevos.

i) En estas sociedades - caracterizadas por una particular orfandad en relación a su propio pasado, y por la heterogeneidad y subalternidad de su herencia - la independencia vino a crear una nueva crisis de identidad. En efecto, fue cortado el vínculo con las metrópolis a comienzos del siglo XIX (a excepción de Cuba), sin que esta circunstancia significara una transformación significativa con relación a las tendencias estructurales ya existentes. En todo caso, a los espectros tradicionales se sumaron otros nuevos. Las elites triunfantes continuaron reproduciendo los mecanismos de exclusión existentes; se preocuparon especialmente con la ampliación o establecimiento de sectores económicos para exportación (con nuevos y decisivos costos ambientales) y llevaron adelante la conquista de nuevos territorios a costa de los pueblos indígenas aún no sometidos, reproduciendo los mecanismos clásicos de la acumulación originaria (REY, 1975; ALIMONDA \& FERGUSON, 2001; GONZÁLEZ \& LEÓN, 2000).

j) Pero, al mismo tiempo, al cortar los vínculos con las metrópolis ibéricas se abrió la posibilidad de un nuevo tipo de vinculación con otras metrópolis, aunque desde el exterior de sus sistemas coloniales. Así, al mismo tiempo que esas nuevas metrópolis establecían los paradigmas de referencia de la modernidad latinoamericana, no hubo sino una interlocución desde un lugar de enunciación subordinada. América Latina no fue parte de la constitución de una cultura política democrática e integradora, como fue el caso de los dominios británicos, ni tampoco participó en pie de igualdad en los avances de la investigación de las ciencias de la naturaleza. El positivismo tuvo más 
significado político que científico-cultural, así como el liberalismo fue más económico que político. El cosmopolitismo, presentado como sinónimo de modernidad, fue frecuentemente un recurso de elitización antidemocrática y, por lo tanto, antimoderno.

k) Así, América Latina llega a la contemporaneidad con una tremenda herencia histórica, "cuyos fantasmas pesan sobre los cerebros de los vivos". La exclusión social y económica y sus consecuencias siguen siendo norma corriente, así como la apropiación oligopólica de los recursos naturales y la depredación ambiental al servicio de la economía de rapiña.

1) Sin embargo, hay elementos positivos. Uno de ellos es que la propia heterogeneidad, como condición concreta de existencia y reproducción de la sociedad, crea la posibilidad de articulaciones plurales y de un riquísimo intercambio de experiencias socio-ambientales alternativas a la lógica de la rapiña, así como de lazos sociales cooperativos y solidarios. Son los espectros de las utopías del pasado andino (FLORES GALINDO, 1988; BURGA, 1988), de las civilizaciones amazónicas o inclusive de las tradiciones libertarias ibéricas (MASJUAN, 2001), combatidos, conjurados, renacidos una y otra vez. En la actual crisis de los paradigmas de la modernidad, la invocación de Mariátegui al socialismo indoamericano adquiere nuevas dimensiones, a partir de un rescate de tradiciones socio-ambientales autóctonas.

m) La propia identidad transnacional latinoamericana, a su vez, se alimenta de esos espectros y de los que fueron creados en la Independencia. Los ejércitos transnacionales de San Martín y Bolívar, las proclamas de la Reforma Universitaria, la intensa continentalización de la política y la cultura en los años 60 y 70 del siglo XX constituyen otra fuente fantasmática de la identidad latinoamericana. Paradójicamente, las fallas de constitución de los Estados Nacionales de la región abren la posibilidad y el fundamento de esa identidad transnacional. Si en la década de 1920 Mariátegui podía proclamar en su revista "Todo lo humano es nuestro", con mucha más propiedad todo latinoamericano puede hoy proclamar como "suyo" el conjunto de la herencia cultural y socio-ambiental del continente.

n) Por último, el mismo cosmopolitismo que tantas veces fue esgrimido como factor esterilizador de las capacidades de creación intelectual del continente, puede, en la actual crisis de los relatos hegemónicos, ser un factor positivo. Desde siempre, la cultura latinoamericana ha estado abierta al diálogo y al intercambio. No aceptando un lugar de enunciación subordinado, hay un espacio enorme disponible para que América Latina participe en la búsqueda y elaboración de alternativas para la crisis planetaria. El Forum Social Mundial de Porto Alegre es apenas un ejemplo de las posibilidades potenciales para esas iniciativas.

Este elenco de elementos espectrales pueden ser válidos, nos parece, para aportar a una agenda de discusión sobre la constitución de una Ecología Política latinoamericana. 


\section{MARX, "FEITIÇOS” Y HERENCIAS}

"Los portugueses inventaron en sus factorías de Guinea el concepto de 'fetiche'... (aplicando) “un término vernáculo y medieval (feitiço) a unas prácticas y unas creencias que les intrigaban ... " SERGE GRUZINSKI (1994)

Si el lector benevolente acepta los postulados anteriores, a pesar de su esquematismo y de su amplitud, quisiera pasar ahora al segundo punto de mi argumentación, aquél que se refiere a la posible "herencia" que una Ecología Política latinoamericana puede pretender usufructuar del legado de Carlos Marx.

Para comenzar, digamos que la posibilidad de ese usufructo se establece precisamente con y por medio de la derrocada de lo que Theodor Shanin (1990) llamó los "cuatro ídolos" (o columnas sagradas, o espectros, o fetiches) que aquejaron a la tradición marxista a partir de su sistematización por la social-democracia alemana y sus continuadores bolcheviques. Para Shanin, estos ídolos que componen lo que él denomina "cuadrángulo de legitimación" son a) el énfasis en la pureza doctrinal como método de organización, más que de análisis, y consecuentemente la constitución de la "ortodoxia" en recurso de consagración del poder político; b) la visión de la ciencia como guía de la historia, disminuyendo el papel de la voluntad y de la acción humana; c) la propia noción de "progreso", vinculada al finalismo y la necesidad histórica, como un efecto de la racionalización creciente y de la aplicación de los conocimientos científicos al dominio de la naturaleza y de la organización de la sociedad; d) las herramientas (necesariamente estatalistas-burocráticas) y las metas u objetivos que de allí se derivan (SHANIN, 1990: 320-340).

Para Shanin, la caída de estos ídolos, destinados a bloquear y descalificar todo pensamiento creativo y crítico, abre la posibilidad de recuperar la riqueza analítica de la obra de Marx, un legado del cual los contemporáneos no tenemos razón para privarnos. Y, al mismo tiempo, se franquea el espacio para reconocer a la tradición socialista como un enorme continente, un "ideopanorama" heteroglósico (RIBEIRO, 2001), donde el marxismo ortodoxo queda reducido apenas a una entre otras líneas posibles de organización político-cultural.

La obra de Shanin está destinada a recuperar uno de esos ámbitos de cuestionamiento crítico, los debates rusos del siglo XIX, de los que participó el propio Marx, y que tuvieron como interrogante central el descubrimiento de las particularidades nacionales en una situación de acumulación originaria en el capitalismo periférico. Como veremos más adelante, mucho de esa discusión tiende puentes plurales hacia los dilemas del pensamiento latinoamericano, incluyendo una perspectiva de Ecología Política.

Un autor preocupado especialmente por la herencia del marxismo y su relación con la Ecología Política es Alain Lipietz (2000). En este caso, el marxismo, entendido como "la aplicación de un método de pensamiento, de un conjunto de representaciones, de algunas hipótesis básicas, como un compás para encontrar rumbos 
y como una guía para la acción social transformadora", tendría todo un "aire de familia" con la Ecología Política. Superada la fetichización del "productivismo" (que privilegia el desarrollo de las fuerzas productivas como un valor absoluto y positivo, pero también a los "productores" como actores políticos estratégicos) y el finalismo histórico que aquejan al pensamiento marxista, los puntos de contacto serían múltiples, basados en una perspectiva de análisis materialista, dialéctica, historicista y destinada a la transformación social. Maxismo y Ecología Política, propone Lipietz siguiendo a Ernest Bloch, comparten el mismo "modelo de esperanza". La apropiación de la herencia marxista por parte de la Ecología Política es para Lipietz absolutamente legítima, pero a condición de que la estructura general del andamiaje teórico del paradigma marxista sea sometida a una cuidadosa revisión.

En el horizonte latinoamericano de este debate debe ser destacada la propuesta de Enrique Leff (1986). Para Leff, el paradigma marxista quedó deslegitimado por carecer de una adecuada comprensión de los procesos de la naturaleza, que no la reducen apenas a un objeto de la práctica humana, y por creer (y sostener como un valor positivo) en la uniformización cultural de las sociedades humanas a partir de la evolución de sus bases tecnológico-productivas.

"La crisis ecológica se sitúa en un campo de externalidad teórica y en un horizonte de temporalidad alejado del referente real de El Capital" (LEFF, 1986: 342). El desafío, entonces, es una reconstrucción del materialismo histórico, para "pensar lo impensado en El Capital” (pp. 344). “Así, el ecomarxismo se plantea como un campo de articulación entre la economía ecológica y la ecología política, capaz de integrar las condiciones ecológicas de la producción, el potencial ambiental del desarrollo sustentable y el poder político del movimiento ambientalista, para construir una racionalidad ambiental” (pp. 335). Lo decisivo aquí será precisamente la consideración de todo aquello que escapa a su reducción a los términos de valor mercantil: la relación entre diversidad cultural y prácticas preservacionistas, los bienes culturales y comunales, los padrones de calidad de vida, los procesos naturales de largo plazo, etc. Siguiendo a Baudrillard, Leff verifica un intento del capital por apropiarse simbólicamente de todo lo que no puede incorporar a su lógica de ganancia, por medio de la resemantización de la naturaleza y de la cultura. Ese sería el campo privilegiado para la (re)construcción teórica del ecomarxismo.

Otra perspectiva latinoamericana es la de Michel Löwy (1995), quién llama la atención para la presencia, en la obra de Marx, de dos concepciones distintas de lo que denomina "dialéctica del progreso". Existiría una dialéctica cerrada, prisionera del desarrollo de las fuerzas productivas, como criterio organizador de su visión de la historia. Pero existiría también una dialéctica abierta, en la cual la historia puede ser al mismo tiempo progreso y catástrofe. ${ }^{2}$ Esta segunda perspectiva, permeable para la consideración de las diferencias históricas y de la diversidad cultural, sería la que indujo a Marx a acercarse a la problemática rusa, y donde radicaría la posibilidad de una herencia por parte de los movimientos eco-socialistas contemporáneos.

Löwy se preocupa, también, por presentar una somera revisión de la tradición marxista posterior, donde verifica la existencia de "una corriente disidente, que retoma 
y desarrolla el esbozo intuitivo de la dialéctica abierta de Marx", y donde se refiere a Rosa Luxemburgo, Trotsky, Mariátegui y Walter Benjamin. Se trata de una galería muy honorable y justiciera, pero que también debería incluir, quizás, a algunos interlocutores rusos de Marx, Danielson por lo menos, quién no solamente lo ayudó a quebrar su firmeza eurocéntrica y su "dialéctica cerrada", sino que también es participante del debate que dio origen al horizonte problemático de Rosa Luxemburgo y de Trotsky.

En América Latina, por su parte, existiría un arraigado ecologismo popular, que no siempre ha sido percibido como tal (MARTÍNEZ ALIER, 1995). Su fundamento es la preservación de formas de vida y de relación con el medio natural amenazadas por la lógica de mercantilización. Ejemplos de esta resistencia, para Löwy, serían el movimiento de Chico Mendes en la Amazonia y el EZLN en México. Lamentablemente, su texto se limita a superponer estas dos narrativas, y a sugerir que el marxismo tiene mucho para enseñar a estos movimientos y también para aprender de ellos, pero sin profundizar en la cuestión de su compatibilización teórica y política.

Ya que el debate se está trabando en relación a la herencia intelectual de Marx, quizás sea una orientación útil incluir en nuestro mapa cognitivo una referencia al inspirado libro de Jacques Derrida, Espectros de Marx (1994). Teórico de la desconstrucción, Derrida se dedica a revisar la herencia marxista precisamente en el territorio fantasmático. Los "espectros" en Marx no son apenas singulares figuras de retórica: constituyen al mismo tiempo la confesión de sus obsesiones profundas y la "desconstrucción" de todas las formas constitutivas de la sociedad burguesa, de su época y de la nuestra.

Derrida está absolutamente en lo cierto cuando comprueba que "espectros" es el primer sustantivo que aparece en el Manifiesto Comunista, y dos veces en la primera frase: "Un espectro ronda a Europa, el espectro del comunismo". Desde su punto de vista, toda la obra de Marx puede ser leída como una especie de tratado sobre los espectros.

Desde luego, una verdadera ópera fantasmática es para Derrida el 18 Brumario, y también desde su primer párrafo. La coyuntura crítica que va de la caída de la Monarquía de Julio y la proclamación de la Segunda República hasta el golpe de estado de Luis Napoleón es leída por Marx como una virtual danza de espectros, y los ejemplos se suceden obsesivamente. Los hombres del presente se visten con disfraces del pasado, y convocan a los fantasmas de la revolución o del orden: los legitimistas borbónicos, la sombra de Napoleón Bonaparte, la Montaña de 1793, "el sobrino por el tío". Ponen en escena nuevamente el drama de la revolución de 1789, del consulado y del imperio, quienes, a su vez, se habían vivido a sí mismos como romanos. ${ }^{3}$

Pero es mucho más lo que nos espera cuando Marx se introduce en el análisis teórico de las categorías centrales de la producción capitalista. Allí todo se ha transfigurado en "feitiços": la mercadería, el dinero, el trabajo, la renta de la tierra, el propio capital. Todos ellos se han erigido a partir de la transmutación de la naturaleza y de las fuerzas vivas de la humanidad, y sin embargo se defrontan con sus creadores como dotadas de un poder sobrenatural. El mundo del capital y de las mercaderías no está constituido por objetos inanimados; al contrario, es un torbellino de apariciones fantasmáticas, un frenético teatro de sombras dominado por los muertos-vivos. Contra 
ellos, Marx esgrime, como un conjuro, su análisis crítico. Sólo que él también está atravesado y poseído por espectros y obsesiones.

Esos espectros y esas obsesiones están presentes, no por debilidad o por inconsistencia, en su propio texto que se constituye como una heterogeneidad irreductible, en una "disjunción" permanente y necesaria. Contra los fantasmas, Marx levanta el estandarte de la ciencia; pero, al mismo tiempo, esa ciencia supone una doble ruptura. Por un lado, por un "pensamiento del saber" que incluye la propia superación de su enunciación, que se confiesa históricamente ligada a su tiempo y, por lo tanto, abre la posibilidad de su crítica y de su denegación en su propia constitución. Por otro lado, porque la obra de Marx, al mismo tiempo que científica, es política y es subversiva de la propia noción de ciencia, convocando con impaciencia para una acción que es siempre excesiva, que atraviesa el presente histórico más allá de cualquier imperativo científico.

Derrida sigue aquí a Maurice Blanchot: "Marx não convive confortavelmente com essa pluralidade de linguagens que sempre se chocam e desunemse nele. Ainda que essas linguagens pareçam convergir para o mesmo fim, elas não teriam meios de serem retraduzidas uma na outra" (BLANCHOT, Apud DERRIDA, 1994: 55). Y luego se pregunta: "Cómo receber, cómo entender una fala, uma vez que ela não se deixa traduzir de si para si mesma?". Pero allí reside justamente el secreto: el legado que se recibe es siempre heterogéneo, y sólo así puede ser aceptado. "A traduzibilidade assegurada, a homogeneidade dada, a coerência sistemática absoluta, eis o que torna seguramente a injunção, a herança e o porvir, numa palavra, o outro, impossíveis" (DERRIDA, 1994: 54/55).

Es obvio sugerir que infinitamente más espectral es nuestro capitalismo contemporáneo, hecho de movimientos embrujados del capital financiero, de super-estados espectrales, de cyberespacio y tecnologías virtuales. Y es justamente por eso que la lucha obsesiva de Marx por conjurar a los espectros está más presente que nunca. "Na ocasião em que uma nova desordem mundial tenta instalar seu neocapitalismo e seu neoliberalismo, denegação alguma consegue desembaraçar-se de todos os fantasmas de Marx. A hegemonia organiza sempre a repressão e, portanto, a confirmação de uma obsessão. A obsessão pertence à estrutura de toda hegemonia” (DERRIDA, 1994: 57-58).

Recibir la herencia de Marx significa también recibir los fantasmas y las obsesiones de su tiempo, donde podemos reconocer los de nuestra época. Y son también sus propios fantasmas y sus propias obsesiones. No es interesante heredar una momia. En general, ni siquiera se recibe un libro de recetas listas donde se vuelca la experiencia culinaria de una abuela mitológica. S i hay un libro, estará en un estante de una cocina de un caserón embrujado, y deberemos ir a buscarlo a la medianoche, y quizás sus páginas estén en blanco ... Talvez lo más valioso de la herencia esté en los reflejos distorsionados de un espejo, que tendremos que aprender a leer.

Como escribió Emilio de Ipola en un bello texto sobre Pancho Aricó: "Marx, Gramsci, Mariátegui, fueron sin duda para Pancho grandes pensadores, pero su grandeza estaba sobre todo (no exclusivamente) en sus borradores, en sus notas al margen, en sus cartas, en lo que se encuentra al azar o mirando de reojo en sus textos, publicados o inéditos (...) esos autores, más allá de sus enunciados y de sus demostraciones, continúan 
hablándonos y nosotros, más allá de las mudanzas de la historia y de las incurias del tiempo, continuamos escuchándolos. Son los clásicos. Se los reconoce en que su obra existe para no ser tomada al pie de la letra y en que, sin embargo, los hechos nuevos no están nunca absolutamente fuera de su competencia. Como dice Borges, los clásicos se leen 'con previo fervor y una misteriosa lealtad" (de IPOLA, 1997: 141-147).

Quizás estas sean pistas útiles para una Ecología Política latinoamericana que quiera clarificar su relación con la tradición marxista. Habrá que reconocer los espectros del pasado que continúan presentes, y aprender como conjurarlos. Tendremos que vernos con los fantasmas del presente y descubrir nuevas invocaciones para afrontarlos. Habrá que asumir los propios "feitiços" y hacerlos trabajar a nuestro favor. Habrá que saber convocar en un mismo texto al conocimiento sobre la naturaleza, a la reflexión sobre la sociedad y a la preocupación política. Y habrá que leer muy cuidadosamente a los clásicos consagrados, y descubrir otros no consagrados, y rescatar perlas del fondo del mar, como parece que alguna vez dijo Walter Benjamin (De IPOLA, 1997: 140).

\section{LOS HORIZONTES DE LA MADRE RUSA ${ }^{4}$}

No deja de ser una ironía que los primeros herederos de Marx hayan sido los socialistas rusos, por los que siempre había sentido una peculiar antipatía, no exenta de preconcepto. Puede decirse con todas las letras: durante la mayor parte de su vida Marx se mantuvo fiel a concepciones nítidamente eurocéntricas. Gracias a la amistad de algunos rusos, como Danielson y Kowalevsky, pudo librarse en parte de ese espectro, por lo menos para poder mirar por la ventana que daba hacia el Este.

Uno de los rusos más detestados por Marx era Alexander Herzen, protector a su vez de sus rivales Proudhom y Bakunin. Pero justamente, si se trata de hablar sobre el descubrimiento de la situación periférica de una sociedad y de sus dilemas consecuentes, Herzen es ineludible. Justamente porque en él, ese descubrimiento supone no un rechazo de lo autóctono ofuscado por la modernidad, como su contemporáneo Sarmiento y otros tantos latinoamericanos. Herzen descubre la periferia al mismo tiempo que la crítica a la modernidad eurocéntrica, y al hacerlo propone justamente regresar a las virtualidades del atraso, otro descubrimiento! Con justo motivo, Isaiah Berlin considera a Herzen, junto con Marx y Tocqueville, uno de los pensadores políticos más relevantes del siglo XIX (BERLIN, 1978).

Nacido en 1812, hijo ilegítimo de un noble, Herzen se forma en la ambición de contribuir para mejorar los destinos del pueblo ruso y librarlo del despotismo. Será preso, deportado a Siberia y, en 1847, parte para el exilio en Europa Occidental. Unos años más tarde escribirá una descripción de su pasaje de la frontera entre Rusia y los Países Bálticos. Curiosamente, sus observaciones sobre el paisaje y los ambientes rurales le inspiran reflexiones que lo aproximan a la Ecología Política. En el aspecto de las aldeas, de sus habitantes y de los campos circundantes, Herzen nota elementos que le permiten concluir diferencias en la organización social. Hay barbarie en la civilización y civilización en la barbarie. 


\begin{abstract}
"Los alemanes del Báltico tienen sobre nosotros la ventaja de poseer normas positivas, bien elaboradas; pertenecen a la gran civilización europea. Nosotros tenemos sobre ellos la ventaja de la fuerza bruta, de un cierto impulso en la espera. (...) Esta antítesis tan tajante, tan exagerada entre Rusia y las provincias del Báltico se reproduce, en su esencia, entre el mundo eslavo y Europa. La diferencia reside en que en el mundo eslavo existe un elemento de civilización occidental en la superficie, y en el mundo europeo un elemento completamente bárbaro en la base" (HERZEN, 1979: 59).
\end{abstract}

Se radica en Paris y le toca presenciar los sucesos de 1848, el mismo espectral teatro de sombras, farsa trágica, que Marx conjuró en el 18 Brumario. En febrero y en junio participa de las manifestaciones populares y de las barricadas. Presencia la represión militar del movimiento, y se desespera: "La revolución caía vencida. La autoridad se imponía a la libertad (...) Después de la insurrección, el terror es terrible. Es un terror retrógrado, con todo el miedo de la burguesía francesa, la parte más estúpida de toda la población europea". Se radica en Niza donde, exilado en el exilio, dará apoyo a otros desterrados rusos y escribirá, en 1850, su libro "El desarrollo de las ideas revolucionarias en Rusia", al que continúa, en 1852, el folleto "El pueblo ruso y el socialismo".

"Es horrible vivir en Rusia, pero también es horrible vivir en Europa", dice en ese libro. "El callejón sin salida al que han llegado los Estados de Europa es manifiesto. Les es necesario lanzarse con fuerza hacia adelante o echarse atrás más de lo que ya lo hacen" (HERZEN, 1979: 206). En 1848 ya había aparecido ante Herzen toda la hipocresía contenida en la modernización económica y política de Europa Occidental. Frente a ello, Rusia, a pesar del despotismo zarista y de la opresión social e ideológica, tiene a su favor "la frescura de la juventud y una tendencia natural a las instituciones socialistas" (ibídem).

"La frescura de la juventud" se refiere a las nuevas generaciones que se inspiran en los ideales de Occidente (esos ideales que Occidente traiciona cotidianamente) para liberar al pueblo y democratizar el país. La "tendencia natural a las instituciones socialistas" invoca a las tradiciones de organización campesina, la obschina, la famosa comuna rural rusa. Allí tiene Herzen a su espíritu benéfico: en esa comuna residen valores de solidaridad humana y de cooperación efectiva, con propiedad colectiva de la tierra. Los campesinos rusos detestan la propiedad privada individual. Lo que para el discurso de la modernización constituye un indicio de 'atraso", de obstáculo al desarrollo de la economía mercantil y de las fuerzas productivas, para Herzen, que inaugura una línea de pensamiento no apenas ruso, la supervivencia de ese atraso significa precisamente la esperanza de que para Rusia será posible, aún, seguir un camino alternativo al de la generalización del capitalismo. Si la crisis de 1848 ya ha puesto de manifiesto la auténtica faz de la modernidad occidental, vale más la pena tomar otro camino.

Fallecido en 1870, Herzen vendrá a ser una figura central en la intensa actividad político-cultural que desarrollarán los revolucionarios rusos en la segunda mitad del siglo XIX. E n el seno de ese movimiento existió un significativo debate sobre los caminos abiertos para el desarrollo del país, donde la supervivencia de la comuna 
rural, confirmando la intuición de Herzen, tendría un papel estratégico. La potencialidad de ese debate, es conocido, contribuyó a que Marx superara su comprensión "cerrada" (o eurocéntrica) del devenir histórico, y considerara, inclusive, en su carta a Vera Zasulitch, de 1872, la posibilidad de que esa comuna rural, liberada de las fuerzas que la oprimían e incorporando tecnología y saberes agrícolas occidentales, pudiese constituir "el núcleo de la regeneración social de Rusia".

Y allí viene la segunda parte de esta historia cuyo protagonista es Nicolai Danielson. En septiembre de 1868, el joven Danielson, empleado de una editorial en San Petesburgo, escribe a Marx consultándolo sobre la posibilidad de publicar una edición rusa de su libro reciente, El Capital, cuyo primer tomo había aparecido en Alemania en 1865. Será la primera carta de una larga correspondencia que se extenderá hasta la muerte de Marx, en 1883, y que luego continuará teniendo a Engels como destinatario. En 1910, el mismo Danielson donó la colección de cartas al Museo Británico, lo que acabó permitiendo su conservación. Y también la recuperación de su memoria: lamentablemente, Danielson es más conocido por las críticas arrasadoras que soportó su obra que por su divulgación, ya que es prácticamente inédito fuera de Rusia. Se siente aquí la vigencia fatal de los "ídolos" de Shanin ...

Diferentes contingencias complican el trabajo de traducción de El Capital, que finalmente es finalizado por Danielson en $1872^{5}$. Puede ser considerado con propiedad, entonces, uno de los primeros especialistas en la obra de Marx. Pero lo interesante es que a través de esa profusa correspondencia Danielson se va transformado primero en informante de Marx acerca de los detalles internos del movimiento revolucionario ruso, y más tarde en su consultor sobre temas de Rusia. Intercambian libros e informaciones bibliográficas, históricas y políticas al punto que Marx empieza a estudiar ruso para poder leer ese material. A pedido de Marx, Danielson prepara un voluminoso informe sobre la formación histórica de la propiedad comunal rusa. Una y otra vez, desde 1869, él insiste en que Marx prepare una obra analítica sobre Rusia. Marx le devuelve la invitación, y lo estimula a que sea el propio Danielson quien la escriba. Finalmente, en 1880 Danielson publica un artículo sobre el proceso de capitalización de la renta agraria. Varios años después, en 1893, ese artículo será parte fundamental de su libro "Ensayos sobre nuestra economía social después de la reforma". Paradójicamente, su obra fue recibida con fuego cerrado por los marxistas "ortodoxos" rusos de la época, especialmente por Lenin, quién lo ataca lapidariamente en su obra "El desarrollo del capitalismo en Rusia”.

Lo interesante de Danielson es justamente que asume como principio de explicación el carácter periférico de la economía rusa en el contexto internacional, y es a partir de allí que se cuestiona sobre la potencialidad real de seguir una vía de desarrollo capitalista. Sus preocupaciones en ese sentido traen ecos hasta las discusiones sobre el "desarrollo del subdesarrollo" latinoamericano, pero hay también un hecho destacable: es el primer teórico de la tradición marxista que expresa una preocupación consistente y recurrente por la degradación ambiental provocada por cierto "modelo de desarrollo". En su obra, Danielson "demostraba la existencia de un crecimiento acelerado del capitalismo en el campo, que en virtud del carácter asumido por la extrema 
concentración del capital, por el papel del crédito y la expansión de la red ferroviaria, tendía a provocar un tipo de desarrollo anómalo cuyas consecuencias finales no podían ser el crecimiento de la economía en su conjunto, sino una crisis prolongada de carácter catastrófico para la suerte del campesinado y de las masas populares rusas. De hecho, el capitalismo no estaba creando en Rusia un orden superior sino descomponiendo a la economía nacional, desbarajustando al conjunto de la organización productiva social (...) No era ya la inminencia de una revolución lo que ponía sobre el tapete el problema del destino de Rusia, sino el modo particular en que se expandía en ese país un sistema que "ponía en peligro la existencia de todo un pueblo" (ARICÓ, 1981: XVI-XVII).

Cuál podía ser la alternativa? "Sólo quedaba la alternativa de desandar un camino que conducía a la catástrofe potenciando el desarrollo de comunidades agrarias en condiciones de posesión directa de los instrumentos de producción y en primer lugar de la tierra. Este proceso sería acompañado de un tipo de industrialización no capitalista basado en la presencia decisoria de la propiedad estatal o pública y en la pequeña industria popular (...) Aparece así, esbozada avant la lettre, la primera tentativa de plantear teóricamente y de resolver en la práctica los problemas del desarrollo desigual y del atraso que motivarían en la segunda posguerra el surgimiento de la problemática del subdesarrollo y de la dependencia" (ARICÓ, 1981: XVIII).

Desafortunadamente para Danielson, su momento de madurez teórica vino a eclodir luego de la muerte de Marx, y, al mismo tiempo en que sufría ataques de todo tipo en Rusia, vino a tener como interlocutor misivista a Engels, él mismo transfigurado en ídolo. Una y otra vez la correspondencia de Danielson intenta hacer comprender a Engels sus puntos de vista; una y otra vez Engels le responde a partir de fórmulas prefabricadas, conjuros europeos contra la barbarie rusa que las propuestas de Danielson parecen representar. De esa forma, era desautorizada una perspectiva de investigación sobre una especificidad nacional cuya orientación original había partido del propio Marx. Y el medio ambiente? El 5 de febrero de 1879, Danielson registra la destrucción forestal causada por los ferrocarriles: "se puede decir que son verdaderos tubos de drenaje que se llevan del organismo nacional el alimento y el suelo. Chuprov (...) habla sobre la influencia de los ferrocarriles en el exterminio forestal: "Inmediatamente al tendido de los ferrocarriles comienza una intensa tala de los bosques cercanos; las cargas de madera aumentan rápidamente en pocos años; luego, a medida que se opera el exterminio de los bosques en los alrededores de la estación, (...) ocurre una disminución de las cargas de madera". "Esta reflexión" continúa Danielson, "se puede aplicar también para las cargas de trigo, pero en este caso el período del agotamiento del suelo resulta más largo. El resultado, sin embargo, es el mismo: por un lado el aniquilamiento forestal, por el otro la mala cosecha o la hambruna" (ARICÓ, 1981: 115-116).

Pero es interesante consignar la respuesta de Marx, especialmente recordando sus famosos artículos de 1853 alabando la construcción de ferrocarriles en la India. No solamente Marx no se escandaliza por el análisis de Danielson, como adelanta una reflexión interesante que permite verificar su percepción de una diferenciación en el espacio del desarrollo capitalista, que ya no tiene como referencia el modelo eurocéntrico como paradigma fatal. Dice Marx: "Por otra parte, la aparición del sistema 
ferroviario en los principales países capitalistas permitió (e incluso obligó) que naciones en las cuales el capitalismo abarcaba sólo a una reducida capa superior de la sociedad, crearan y ampliaran repentinamente su superestructura capitalista en una medida enteramente desproporcionada al conjunto del organismo social. Por eso no cabe la menor duda de que en esos estados el ferrocarril ha acelerado la desintegración social y política, de la misma manera que en los estados más desarrollados ha acelerado la transformación de la producción capitalista". Y más adelante vuelve con una referencia al libre comercio y la globalización: "En general, los ferrocarriles dieron un inmenso impulso al desarrollo del comercio exterior, pero en los países que exportan principalmente materias primas, el comercio aumentó la miseria de las masas (...) porque desde el momento en que toda producción local pudo convertirse en oro internacional, muchos artículos anteriormente baratos (...) encarecieron y desaparecieron del consumo popular, en tanto que la producción misma se transformó de acuerdo a su adaptabilidad a la exportación" (Marx a Danielson, 10 de abril de 1879).

Las cartas se suceden, y Danielson abruma a Marx con cuadros estadísticos, información erudita y reflexiones sobre el "modelo de desarrollo" ruso. El 17 de marzo de 1880 se lamenta porque se están abandonando las obras que permiten la regulación de las condiciones naturales de la producción (irrigación, drenajes) y Rusia está quedando a merced del clima. Y agrega: "En la actualidad, la actividad económica del país está determinada por una explotación de rapiña cada vez mayor, ejercida por la población urbana sobre la población rural", constatando cómo aumenta la diferenciación interna del campesinado.

Finalmente, Marx estimula a Danielson a que transforme sus cartas en un artículo. Danielson sigue el consejo y el artículo se publica, pero tiene muy mala recepción, y en carta a Marx le cuenta que está siendo boicoteado. El 19 de febrero de 1881 Marx le escribe: "He leído con enorme interés su artículo, original en el mejor sentido de la palabra. A esto se debe el boicot: si usted rompe las reglas rutinarias del pensamiento, puede estar seguro de que siempre será boicoteado; es la única arma de defensa que en su perplejidad saben manejar los rutinarios". A continuación, desarrolla unas reflexiones sobre la capacidad del suelo agrícola para reconstituir su fertilidad.

La correspondencia acaba en 1883, con la muerte de Marx. Se inicia entonces una segunda fase, ahora de intercambio epistolar Danielson/Engels. Las discrepancias tan elocuentes, y en fecha tan temprana de la idolización del marxismo, llegan a ser dramáticas. Durante varios años la correspondencia se mantiene concentrada en temas vinculados con la organización de las ediciones de El Capital, y con intercambio de noticias sobre amigos comunes. Danielson pide a Engels que le remita sus cartas que han quedado en casa de Marx, que forman la colección que luego irá al Museo Británico.

El 12 de noviembre de 1891, Danielson escribe a Engels: "Quiero llamar la atención sobre la especificidad de nuestra situación: nos incorporamos al mercado mundial en la etapa en que debido al progreso técnico predomina el modo capitalista de producción". Siguiendo un análisis que refiere a la problemática del "capitalismo tardío", reflexiona sobre la desproporcionalidad de desarrollo entre agricultura atrasada e industria altamente concentrada y tecnificada, pero paradójicamente orientada hacia un mercado 
interno escuálido, que no puede crecer por causa del pauperismo campesino. "En otras palabras, el desarrollo del capitalismo reduce su propio mercado”.

Engels responde con la serie de fórmulas que se están constituyendo como corolarios explicativos de toda la historia posible, en el contexto de la idolización del marxismo: "Nada se puede hacer en contra de los hechos económicos. Hoy la regla es la gran explotación rural con maquinaria, que se convierte cada vez más en el único modo posible de explotación agrícola. De tal modo que, en la actualidad, el campesino parece estar condenado a la ruina (...) En lo que se refiere a la tala de bosques, tanto como a la ruina de los campesinos, es una condición esencial de vida de la sociedad burguesa. No hay país civilizado de Europa que no haya experimentado esa situación. (...) Mientras tanto, no nos queda otro remedio que consolarnos con la idea de que todo ha de servir, en última instancia, a la causa del progreso de la humanidad" (Engels a Danielson, 15 de marzo de 1892).

Son necesarios más ejemplos para calificar la diferencia de interlocución entre estos dos hombres? Mientras Danielson, a partir de la observación y el análisis de un proceso histórico concreto, adelanta una hipótesis decisiva para la comprensión del desarrollo capitalista tardío o periférico (de donde se deduce la urgencia de buscar alternativas externas a la tendencia dominante), Engels responde con un "artefacto" pre-fabricado, y que se resume a comprobar que Rusia está en el mejor de los mundos posibles y que se debe apoyar el desarrollo del capitalismo, a pesar de toda la catástrofe social que lo acompaña. En realidad, en este diálogo Engels parece un precursor de la "jihad" neoliberal que arrasa América Latina desde hace dos décadas, como "la única política posible", "el final del populismo", etc.

El 3 de octubre de 1892, Danielson, cada vez más nuestro contemporáneo (o será América Latina quién se aproxima a él?) escribe: "Transcurridos treinta años del actual régimen hemos llegado a la crisis. No a una crisis de producción, del dinero o alguna otra crisis parcial, sino a una que está socavando toda nuestra existencia social y económica. El capitalismo ha liberado a muchos millones de trabajadores, pero sólo ha dado trabajo a un millón; al agotar los suelos, al aniquilar bosques sobre grandes extensiones, al desecar las fuentes de todos los ríos, originó sus propias crisis (...) su base se encuentra en el agotamiento de los suelos, son crisis que dependen de la completa sumisión del hombre a la naturaleza, crisis que subsumen la forma capitalista de producción en dependencia de fenómenos meteorológicos, de tal modo que el último año $40 \%$ de la población rusa conoció el hambre”.

Finalmente, el 3 de noviembre de 1893, en la que quizás sea su carta más dramática, Danielson avanza sobre la idea de un desarrollo capitalista que destruye no solamente sus propias condiciones de reproducción (a la manera de lo que O'Connor 1991 - ha denominado "la segunda contradicción del capitalismo"), sino que depreda inclusive a las propias relaciones sociales básicas constituyentes de la sociedad, al estilo del neocapitalismo conservador latinoamericano, que se aplica sobre relaciones sociales y políticas mucho menos consolidadas que las del capitalismo central. En esas condiciones, Danielson no entiende porqué debería cumplirse la norma metafísica de que el resultado debería ser una maduración de condiciones y sujetos revolucionarios. 
"En mi opinión, el aspecto positivo del modo de producción capitalista no contrarresta su aspecto negativo: el lado progresista tiene repercusiones en una porción muy reducida de la población, mientras que el lado negativo abarca a la mayor parte. La evolución de este modo de producción detiene su propio desarrollo; esto significa que debemos buscar otra salida; será inútil esperar formas más altas de desarrollo como consecuencia ineluctable del modo de producción capitalista y del antagonismo social creado por él".

"Acaso la hambruna de 1891 no dejó huellas? Lo que ocurrió en el año de hambruna representa la forma atenuada de lo que podemos esperar para el futuro. No tuvo ninguna fuerza de creación. Qué nos enseñó dicho año? Qué hay que hacer para librarse de la repetición de esa calamidad? Se nos dice que tal calamidad no sólo es inevitable, sino que en el futuro cobrará un aspecto más agudo; no hay salida, y en un futuro cercano se esperan enormes sufrimientos y el despilfarro de vidas humanas; y finalmente, cuando a partir de este modo de producción (que es la causa directa de dichos sufrimientos) estalle el antagonismo social que él genera, podremos esperar el desarrollo de una forma más elevada. Y si el modo de producción capitalista no genera un antagonismo dualista como el que se produjo en Europa Occidental? Y si el desarrollo de este modo crea los obstáculos para su propio desarrollo?

"Los resultados del desarrollo del capitalismo en un país de alta cultura y en un país de cultura rudimentaria son totalmente diferentes. En el primer caso, este desarrollo lleva a la formación de una fuerza organizada, consciente de su influencia; en el otro, en cambio, desbarajusta al conjunto de la organización productiva social; lleva al inmenso despilfarro de vidas humanas y de fuerzas productivas, ya que proporciona trabajo a una parte cada vez menor de la población, al mismo tiempo en que disminuye el nivel económico de toda la población (...) El capitalismo crea obstáculos tan grandes para su propio desarrollo que el paso a una forma más elevada resulta imposible".

En resumen: creo no estar muy equivocado al pensar que estos debates tienen plena actualidad en relación con la constitución de una Ecología Política latinoamericana.

\section{BIBLIOGRAFIA}

ALIMONDA, H. \& FERGUSON, J. "Imagens, deserto e memória nacional: as fotografias da campanha do Exército argentino contra os índios da Patagônia - 1879", In: Ángela Mendes de ALMEIDA, A.M. et al. De sertões, desertos e "espaços incivilizados", Rio de Janeiro, Mauad, 2001.

ARICÓ, J. (org.) Karl Marx, Nikolai Danielson, Friedrich Engels - Correspondencia 1868 - 1895, México, Siglo XXI, 1981.

BENSAID, D. Marx, o Intempestivo, Rio de janeiro, Civilização Brasileira, 1999.

BERLIN, I. Pensadores rusos, México, Fondo de Cultura Económica, 1978.

BIRNBAUM, P. \& CHAZEL, F. Teoria Sociológica, São Paulo, HUCITEC/Edusp, 1977. BURGA, M. Nacimiento de una utopía - Muerte y resurrección de los incas, Lima, Instituto de Apoyo Agrario, 1988. 
CASTRO HERRERA, G. Naturaleza y Sociedad en la Historia de América Latina, Panamá, CELA, 1996.

CROSBY, A. Imperialismo Ecológico, São Paulo, Companhia das Letras, 1993.

DERRIDA, J. Espectros de Marx - O estado da dívida, o trabalho do luto e a nova Internacional, Rio de Janeiro, Relume Dumará, 1994.

De IPOLA, E. Las cosas del creer (Creencia, lazo social y comunidad política), Buenos Aires, Ariel, 1997.

FERRÃO, J. M. A aventura das plantas e os descobrimentos portugueses, Lisboa, Instituto de Investigação Científica Tropical, 1992.

FLORES GALINDO, A. Buscando un Inca: Identidad y Utopía en los Andes, Lima, Horizonte, 1988.

GONZÁLEZ, C. \& LEÓN, R. Historia de los pueblos indígenas de México - Civilizar o Exterminar, Tlalpan, CIESAS/INI, 2000.

GRUZINSKI, S. La guerra de las imágenes (De Cristóbal Colón a "Blade Runner 1492/2019), México, Fondo de Cultura Económica, 1994.

HERNÁNDEZ BERMEJO, J. \& LEÓN, J. Cultivos marginados, otra perspectiva de 1492, Roma, FAO, 1992.

HERZEN, A. El desarrollo de las ideas revolucionarias en Rusia, México, Siglo XXI, 1979.

JAMESON, F. Pós-modernismo - A Lógica Cultural do Capitalismo Tardio, São Paulo, Ática, 1996.

LEFF, E. Ecología y Capital, México, Siglo XXI, 1996.

LIPIETZ, A. "Political Ecology and the Future of Marxism", Capitalism, nature, socialism, March 2000.

LÖWY, M. "De Karl Marx a Emiliano Zapata: la dialéctica marxiana del progreso y la apuesta actual de los movimientos eco-sociales”, Ecologia Política, n. 10, Barcelona, 1995.

MARIÁTEGUI, J. C. Siete Ensayos de Interpretación de la realidad peruana, Lima, Amauta, 1995.

MARTÍNEZ ALIER, J. De la Economía Ecológica al Ecologismo Popular, Montevideo, Nordan - Comunidad/Icaria, 1995.

MASJUAN, E. La Ecología Humana del Anarquismo Ibérico, Barcelona, Icaria, 2001. O'CONNOR, J. "La segunda contradicción del capitalismo: sus causas y consecuencias", El cielo por asalto, 2, Buenos Aires, otoño 1991.

POLANYI, K. The Great Transformation, Boston, Beacon Press, 1957.

REY, P.-P. Las alianzas de clase, México, Siglo XXI, 1975.

RIBEIRO, G. L. "Post-imperialismo: para una discusión después del post-colonialismo y del multiculturalismo", In: Mato, D. (compilador), Estudios latinoamericanos sobre cultura y transformaciones sociales en tiempos de globalización, Buenos Aires, CLACSO, 2001.

SHANIN, T. El Marx tardío y la vía rusa - Marx y la periferia del capitalismo, Madrid, Revolución, 1990.

RAMA, Á. A Cidade das Letras, São Paulo, Brasiliense, 1985. 
TROTSKY, L. História da Revolução Russa, Rio de Janeiro, Saga, 1967. TUDELA, F. "El encuentro entre dos mundos: impacto ambiental de la conquista", Nueva Sociedad, 122, Caracas, noviembre 1992.

\section{NOTAS}

* CPDA-UFRRJ. Programa de Postdoctorado, Centro de Centro de Estudios Sociológicos, El Colegio de México, como becario de CAPES. Coordinador del Grupo de Trabajo en Ecologia Política (Consejo Latinoamericano de Ciencias Sociales).

${ }^{1}$ Este punto constituye una preocupación central en los trabajos de ROSA LUXEMBURGO, especialmente "La Acumulación del Capital" e "Introducción a la Economía Política".

${ }^{2}$ MICHEL LÖWY sigue en éste punto a JAMESON (1996).

${ }^{3}$ Cabe recordar aquí una observación de ERNEST BLOCH en su Thomas Munzer: "Marx concede lugar a las exaltaciones religiosas, por lo menos en el primer período de toda gran revolución, en la medida en que los nuevos señores se sintieron romanos nuevos, paganos nuevos, en la medida en que los campesinos alemanes, como lo harían más tarde los puritanos para su revolución burguesa, tomaron prestado al Viejo Testamento su vocabulario, sus pasiones e ilusiones; en la medida en que también la Revolución Francesa se adornó con los títulos, con las palabras de orden, con las costumbres del Consulado y del Imperio Romano (...) En el caso particular de la Guerra de los Campesinos, con toda su poderosa actividad de fabricación, de comercio de imágenes, con todo su espiritualismo, es imposible (...) no considerar su elemento esencial y primitivo: el arrobado querer de una caminata que lleva directamente al paraíso" (citado por BIRNBAUM \& CHAZEL, 1977: 408). Ver también los interesantes comentarios de Trotsky (1967, cap. 1).

${ }^{4}$ Por razones prácticas, evitaré referirme a la situación histórica y política de Rusia en el siglo XIX, lo que haría este texto interminable y lo alejaría de sus objetivos. Afortunadamente, existen excelentes estudios disponibles.

${ }^{5}$ Un detalle delicioso para los interesados en fotografía (o en censura). E n una de las primeras cartas, Danielson solicita a Marx un "fotograma" con su retrato para ser incluido en el libro. Marx lo remite a vuelta de correo. Finalmente, cuando la primera traducción de El Capital pasa por la censura zarista, el texto es autorizado luego de un examen que dura tres (3) días, pero no el "fotograma". Insólita aparición/ desaparición de un espectro! A los censores les pareció más subversiva la imagen de Marx que su libro? O el "fotograma" fue confiscado por un censor admirador de Marx, seducido por El Capital en régimen de lectura veloz? El parecer de la censura es también delicioso: "Aunque el autor tiene convicciones absolutamente socialistas y todo su libro tiene un carácter decididamente socialista (...) la exposición no puede, de ninguna manera, considerarse accesible. Por otra parte, en el método de demostración siempre se utilizan fórmulas matemáticas, estrictamente científicas. El comité (...) se decide por su publicación" (Danielson a Marx, 23 de mayo de 1872). 